\title{
In-situ HDO of guaiacol over nitrogen-doped activated carbon supported nickel nanoparticles
}

\author{
Wei Jin a , Laura Pastor-Pérez" a,b, Juanjo J. Villora-Picó ${ }^{\mathbf{b}}$, Mercedes M. Pastor-Blas ${ }^{\mathbf{b}}$, \\ Antonio Sepúlveda-Escribano ${ }^{\text {b }}$, Tomás R. Reina ${ }^{a}$, \\ a. Department of Chemical and Process Engineering, University of Surrey, Guildford, GU2 \\ $7 X H$, United Kingdom \\ b. Laboratorio de Materiales Avanzados, Departamento de Química Inorgánica - Instituto \\ Universitario de Materiales de Alicante, Universidad de Alicante, Apartado 99, E-03080 \\ Alicante, Spain
}

Corresponding authors: l.pastorperez@surrey.ac.uk

\begin{abstract}
In-situ hydrodeoxygenation of guaiacol over Ni-based nitrogen-doped activated carbon supported catalysts is presented in this paper as an economically viable route for bio-resources upgrading. The overriding concept of this paper is to use water as hydrogen donor for the HDO reaction suppressing the input of external high-pressure hydrogen. The effect of nitrogen sources, including polyporrole (PPy), polyaniline (PANI) and melamine (Mel) on the structural, electronic and ultimately of catalytic features of the design materials have been addressed. Nitrogen-doped samples, are more active than the undoped counterparts in the " $\mathrm{H}_{2}$-free" HDO process. For instance, the conversion of guaiacol increased by $8 \%$ for $\mathrm{Ni} / \mathrm{PANI}-\mathrm{AC}$ compared to that of $\mathrm{Ni} / \mathrm{AC}$ catalysts. The superior performance of $\mathrm{Ni} / \mathrm{NC}$ can be attributed to the acid-base properties and modified electronic properties which favours the C-O cleavage and water activation as well as enhances dispersion of Ni particles on the catalysts' surface.
\end{abstract}

Keywords: Biomass upgrading, hydrodeoxygenation, nitrogen doped carbon, Ni-based catalysts.

\section{Introduction}

The increasing energy demand and climate change call on the utilization of sustainable and low-carbon energy to ease the over-dependency on limited fossil fuels. Over the recent decades, biomass has become the centre of attention among renewable sources considering its distinctive features, such as low price, low-carbon emission, abundant storage and wide distribution [1]. The statistics show that proportion of bioenergy is approximately $11 \%$ (44.3 EJ) of the world's total primary energy supply [2]. Lignocellulose feedstocks can be transformed into bio-oil through pyrolysis technology. However, biooil directly produced from fast pyrolysis contains high content of oxygen (up to $60 \mathrm{wt. \%}$ ) [3]. Undoubtedly, an upgrading process is indispensable to reduce the oxygen content, which can improve the thermal and chemical properties such as stability, heating value, etc. Catalytic hydrodeoxygenation (HDO) is a fundamental process for upgrading bio-oil before producing high valued chemicals or transportation fuels. In traditional HDO process, oxygen can be removed in the form of water with the participation of high pressure $\mathrm{H}_{2}$.

As cornerstones in the chemical industry [4], catalysts maintain the centre status in both research and industrial field. Typically, although noble metal catalysts such as $\mathrm{Au}, \mathrm{Pd}, \mathrm{Ru}, \mathrm{Rh}$ [5] and $\mathrm{Pt}$ [6], show high activity in HDO process, their industrial application are limited by the high cost and scarcity. The development of efficient non-noble catalysts is undoubted the direction of long-term effect for catalysis community. Among non-noble metal catalysts, Ni-based catalysts are promising candidates in HDO process considering their intrinsic high hydrogenation ability [7]. Carbon materials own the advantages of a lower affinity for coke deposition compared to acidic supports in HDO reactions [8]. The recently developed $\mathrm{N}$-doped carbon (NC) materials have been recognized as promising materials which can be 
used as support in heterogeneous catalysis. The enhanced catalytic performance results from (1) the improvement in hydrophilicity and basicity of supports [9], which could enhance the interaction between substrate and support in aqueous reaction system; (2) the lower dissociation energy for $\mathrm{H}_{2}$ activation results from the modified electronic structure of the carbon matrix and the tuned activity of the $\mathrm{sp}^{2}$ carbon and metal particles [10,11]; (3) N-dopants in the carbon structure can be regarded as favourable anchoring sites or defects for the enhancement of the particle nucleation and reducing the particle size [12]. For instance, as it can be expected that $\mathrm{PtCo} / \mathrm{NOMC}$ (nitrogen-doped ordered mesoporous carbon) is highly effective for HDO of phenolic compounds, with almost full deoxygenation (HDO degree $>99 \%$ ) and cycloalkanes as the produces [13]. The superior performance of N-doped carbon supported catalyst can also be observed in Nie et al. 's investigation [14]. It is reported that the $\mathrm{Pd} / \mathrm{NMC}$ (nitrogen-enriched mesoporous carbon) exhibits 2.9 times higher activity compared to nitrogen-free catalysts, with $100 \%$ conversion of vanillin. The outstanding performance of $\mathrm{Pd} / \mathrm{NMC}$ can be attributed to the percentage change of electron-deficient $\mathrm{Pd}\left(\mathrm{Pd}^{\&+}\right)$ particles arising from the doping of $\mathrm{N}$ together with the co-existence of $\mathrm{Pd}^{\&+}$ and $\mathrm{Pd}^{0}$ resulting from the $\mathrm{Pd}-\mathrm{N}$ interaction [14]. Nowadays, NC support mainly is used in noble metal catalysts. However, to the best of our knowledge, few research investigated the performance of non-noble Ni metal supported on NC in HDO reactions [15].

Doping nitrogen in carbon matrix can be achieved via different routes, including chemical vapour deposition, thermal treatment with $\mathrm{NH}_{3}$ or nitrogen plasma treatment [16]. Generally, bulk properties of the material are not modified to a large extent via these routes [17]. In contrast, the use of carbon precursor with already containing nitrogen atoms is more advisable since the doping of nitrogen can be homogeneously distributed both throughout the bulk and the surface of material. Conducting polymers, such as polypyrrole and polyaniline have been extensively used as nitrogen source for preparing Ndoped carbons. They own the advantages such as cheap and easy to prepare, also the textual properites of $\mathrm{N}-\mathrm{C}$ can be tailored by activation treatment. Another important source of nitrogen, melamine, is a common and inexpensive material which can produce $\mathrm{N}-\mathrm{C}$ via co-pyrolysis process [18]. In the nitrogen doping process, melamine decomposes and sublimes, favouring the incorporation of the $\mathrm{N}$ atoms to the carbonaceous material, when it is treated at temperatures above $350^{\circ} \mathrm{C}[19]$. In this work, a mesoporous $\mathrm{N}$-doped carbon material is required since it is suitable to be used in liquid phase reactions with relatively large molecules as reactants. In this sense, $\mathrm{N}-\mathrm{C}$ were prepared by polymerization of pyrrole and aniline on the surface of a commercial mesoporous carbon. Besides, melamine was also used as nitrogen source in which melamine was co-pyrolysis with AC to dope nitrogen on the surface of AC.

Obtaining a suitable catalyst is indeed of paramount importance to achieve high HDO performances. Along with the catalysts, the reaction conditions and engineering approaches plays a crucial role. In this sense, novel strategies including catalytic transfer hydrogenation, reforming and HDO, metal hydrolysis and HDO, non-thermal plasma, self-supported hydrogenolysis and water assisted in-situ HDO,[20, 21] have been proposed for bio-oil upgrading. All these strategies share a common spirit: suppression of external $\mathrm{H}_{2}$ supply to minimize potential risk in terms of transportation and storage as well as improving the process economic feasibility. Among these " $H_{2}$-free" HDO strategies, water assisted in-situ HDO is perhaps the most promising from an economic perspective and the most challenging from the catalysis side. Water owns multiple excellent features such as cheap, non-toxicity, operationally safe to use, naturally abundant and readily available. Water is typically used as solvent in conventional liquid phase HDO reactions [22-24]. However, few studies investigated the in-situ HDO of bio-oil or model compounds by using water as hydrogen source $[25,26]$.

Under these premises, this study is a proof of concept of an innovative approach for HDO strategy in hydrothermal conditions suppressing the supply of external $\mathrm{H}_{2}$. For this purpose, a series of Ni-based catalysts supported on AC or NC have been prepared, characterized and studied using guaiacol as model compound within the HDO process which is conducted in a batch reactor under mild reaction conditions. The effect of N-doping on the catalysts' properties and ultimately in the HDO performance 
was also a subject of this study which was conceived to inspire the catalysis and biomass community to look into innovative alternatives for bio-resources valorisation

\section{Materials and methods}

\section{Materials}

Chemicals used for $\mathrm{NC}$ synthesis, including pyrrole, aniline, ammonium persulfate, melamine and nickel nitrite hexahydrate $\left(\mathrm{Ni}\left(\mathrm{NO}_{3}\right)_{2} \cdot 6 \mathrm{H}_{2} \mathrm{O}\right)$ were all supplied by Sigma Aldrich. Commercial activated carbon (RGC 30) was provided by Westvaco. Guaiacol, solvent (ethyl acetate and acetone) and chemicals used for calibration (including phenol, o-cresol and catechol) were all supplied by SigmaAldrich Co., Ltd.

\section{Methods}

\section{Catalyst preparation}

Polypyrrole and polyaniline supported on a commercial activated carbon RGC-30 (AC) (PANI-AC and PPy-AC) were prepared via oxidative polymerization. The AC $(0.6 \mathrm{~g})$ was dispersed in $150 \mathrm{ml}$ of acetone and was sonicated $30 \mathrm{~min} .3 \mathrm{mmol}$ of the monomers (aniline and pyrrole) were dissolved in $100 \mathrm{ml}$ of water and the solution was added to the dispersion of the AC. The mixture was stirred $30 \mathrm{~min}$ and the $6 \mathrm{mmol}$ of the oxidant (Ammonium persulfate) previously dissolved in $100 \mathrm{ml}$ of water was added drop by drop in continuous stirring. After 4 hours, the reaction mixture was filtered, washed and dried at $80 \mathrm{~h}$ for 24 hours. The dried sample was pyrolyzed for 4 hours at $900^{\circ} \mathrm{C}$ under flowing $\mathrm{N}_{2}$ $(50 \mathrm{ml} / \mathrm{min})$, with a heating rate of $5^{\circ} \mathrm{C} / \mathrm{min}$, in order to obtain the N-doped carbon. For the preparation of the Mel-AC support, the $\mathrm{AC}$ and melamine were mixed intimately, and the mixture was treated in a tubular furnace for 1 hour at $800^{\circ} \mathrm{C}$ under flowing $\mathrm{N}_{2}(50 \mathrm{ml} / \mathrm{min})$, with a heating rate of $3^{\circ} \mathrm{C} / \mathrm{min}$.

The $\mathrm{Ni} / \mathrm{NC}$ and $\mathrm{Ni} / \mathrm{AC}$ were prepared via wet impregnation to obtain $15 \mathrm{wt} \%$ of Ni. Firstly, $\left(\mathrm{Ni}\left(\mathrm{NO}_{3}\right)_{2} \cdot 6 \mathrm{H}_{2} \mathrm{O}\right)$ was dissolved in acetone. Secondly, the dried activated carbon (AC) or nitrogendoped carbon (NC) were added into the solution with stirring. The solvent was slowly removed under vacuum at $60^{\circ} \mathrm{C}$. Finally, the metal catalysts were dry at $80^{\circ} \mathrm{C}$ for 24 hours and calcined 1 hour at $800^{\circ} \mathrm{C}$ under flowing $\mathrm{N}_{2}$. The samples obtained were labelled as Ni/AC, Ni/PANI-AC, Ni/PPy-AC and Ni/Mel$\mathrm{AC}$.

\section{Catalyst characterization}

XRD. X-Ray powder diffraction patterns were recorded on a Bruker D8-Advance with a Göebel mirror and a Kristalloflex K 760-80 F X-Ray generation system, fitted with a $\mathrm{Cu}$ cathode and a Ni filter. Spectra were registered between 20 and $80^{\circ}(2 \theta)$ with a step of $0.05^{\circ}$ and a time per step of $3 \mathrm{~s}$.

TPR. Temperature programmed experiments were conducted in a conventional U-shaped quartz reactor. For Temperature programmed reduction with $\mathrm{H}_{2}\left(\mathrm{H}_{2}\right.$-TPR) a gaseous mixture of $5 \% \mathrm{H}_{2} / \mathrm{He}$ and flow rate of $50 \mathrm{~mL} / \mathrm{min}$, with a heating rate of $10^{\circ} \mathrm{C} / \mathrm{min}$ was used. Prior the TPR runs, the catalyst was pretreated with $\mathrm{He}(50 \mathrm{~mL} / \mathrm{min})$ at $150^{\circ} \mathrm{C}$ for $1 \mathrm{~h}$. For the temperature programmed desorption a flow rate of $50 \mathrm{~mL} / \mathrm{min}$ of $\mathrm{He}$, with a heating rate of $10{ }^{\circ} \mathrm{C} / \mathrm{min}$ was used. The gasses of interest were followed by on-line mass spectrometry (Pfeiffer, OmniStar GSD 301).

$\mathbf{N}_{2}$ Adsorption Isotherms. The textural properties of the supports were characterised by nitrogen adsorption-desorption measurements at $-196{ }^{\circ} \mathrm{C}$ in an AUTOS-ORB-6 fully automated manometric equipment. The samples were out-gassed under vacuum at $250{ }^{\circ} \mathrm{C}$ for $2 \mathrm{~h}$ before each measurement. The BET equation was applied to estimate the specific surface area.

XPS. XPS measurements were performed with a K-ALPHA spectrometer (ThermoFisher Scientific) operated in the constant energy mode with survey scan pass energies of $200 \mathrm{eV}$ and narrow scan energies of $50 \mathrm{eV}$, to measure the whole energy band as well as selectively measure particular elements. All XPS spectra were acquired using Al-K $\alpha$ radiation $(1486.6 \mathrm{eV})$, with a twin crystal monochromator, 
yielding a focused X-ray spot (elliptical in shape with a major axis length of $400 \mu \mathrm{m}$ ) at $3 \mathrm{~mA} \times 12 \mathrm{kV}$. Charge compensation was attained with the system flood gun, which provides low energy electrons and low energy argon ions from a single source. For the reference binding energy, the $\mathrm{C} 1 \mathrm{~s}$ core level was used, located at $284.6 \mathrm{eV}$. All samples were reduced ex-situ at $800{ }^{\circ} \mathrm{C}$, and before recording the spectrum, the samples were maintained in the analysis chamber until a residual pressure of ca. $5 \times 10^{-7}$ $\mathrm{N} / \mathrm{m}^{2}$ was reached.

TEM. Conventional TEM analysis was carried out with a JOEL model JEM-210 electron microscope working at $200 \mathrm{kV}$ and equipped with a INCA Energy TEM 100 analytical system and a SIS MegaView II camera. Samples for analysis were suspended in methanol and placed on copper grids with a holeycarbon film support.

\section{Catalytic reactions}

The HDO reactions were conducted in a high-pressure batch reactor (Parr Series 5500 HPCL Reactor with a 4848 Reactor Controller) using PTFE gaskets. Catalysts were pre-treated at $400{ }^{\circ} \mathrm{C}$ for $1 \mathrm{~h}$ in a $100 \mathrm{ml} / \mathrm{min}$ gas flow $\left(\mathrm{H}_{2}: \mathrm{N}_{2}=1: 4\right)$ before being used in the $\mathrm{HDO}$ reaction. $1 \mathrm{wt} . \%$ of guaiacol in water $(0.5 \mathrm{~g}$ guaiacol) and $0.2 \mathrm{~g}$ of catalyst were loaded in a glass-lined steel vessel. To avoid any air contamination, $\mathrm{N}_{2}$ was bubbled through the solution for 5 min under a stirring speed of $300 \mathrm{rpm}$ before closing the reaction vessel. Then, the reactor was heated to the desired temperature $\left(250{ }^{\circ} \mathrm{C}\right)$ and hold at this temperature of $4 \mathrm{~h}$ under a stirring speed of $300 \mathrm{rpm}$. The pressure of the vessel which mainly generated by high temperature liquid in the vessel was approximate 50 bar during the reaction. After the reaction, the spent catalyst was recovered from the liquid by filtration, washing and drying treatment. The organic products were dissolved and recovered by ethyl acetate extraction.

The organic products were identified by gas chromatograph-mass spectrometry (GC-MS). Quantitative analysis was performed with a gas chromatograph-flame ionisation detector (GC, Shimadzu; FID: Agilent cellular model). The injector temperature was kept at $280^{\circ} \mathrm{C}$. The GC separation was performed using a Carboxen Packed Analytical Column $(30 \mathrm{~m} \times 320 \mu \mathrm{m} \times 0.25 \mu \mathrm{m})$. A split ratio of 20:1 was held. The column was firstly held at $50{ }^{\circ} \mathrm{C}$ for $1 \mathrm{~min}$, then increased to $240{ }^{\circ} \mathrm{C}$ at a heating rate of $5{ }^{\circ} \mathrm{C} / \mathrm{min}$ and held at $240{ }^{\circ} \mathrm{C}$ for $10 \mathrm{~min}$. Reactant and typical products were quantified based on the external standard method.

The conversion of guaiacol, the selectivities towards typical products (based on $\mathrm{C}$ mol) and HDO conversion ratio were calculated using $E q 1, E q 2$ and $E q 3$ [27]:

$$
\begin{aligned}
& \text { Conversion of guaiacol }=\frac{n_{G U A, \text { in }}-n_{G U A, \text { out }}}{n_{G U A, \text { in }}} \times 100 \% \\
& \text { Selectivity of product } x=\frac{n_{x} \times N_{x}}{\left(n_{G, \text { in }}-n_{G, \text { out }}\right) \times N_{G U A}} \times 100 \% \quad \text { Eq. } 2 \\
& \text { HDO conversion: } \mathrm{X}_{\mathrm{HDO}} \%=100 \times\left(1-\frac{(n P H E+n C R E+2(n G U A, \text { out }+n C A T))}{2(n G U A, \text { in })}\right) \quad E q .3
\end{aligned}
$$

$n_{G U A, \text { in }}$ : Initial mole of guaiacol; $n_{G U A, \text { out }}$ : Detected mole of guaiacol in the organic phase; $n_{x}$ : Mole of product $x$.

$N_{G U A}$ : Number of carbon in guaiacol; $N_{x}$ : Number of carbon in product $x$.

GUA: guaiacol; PHE: phenol; CRE: o-cresol; CAT: catechol

\section{Results and discussion}

\section{Characterization of supports and calcined catalysts \\ $\mathbf{H}_{2}$-TPR}

Figure 1 shows the $\mathrm{H}_{2}$-temperature-programmed reduction (TPR) analysis of all calcined catalysts. It is observed that the reduction profiles of all samples show a broad band which can be split in two typical 
consumption peaks. The sharp peak at a low temperature range $\left(250-300{ }^{\circ} \mathrm{C}\right)$ corresponds to the reduction of finely dispersed $\mathrm{NiO}$ on the support. It should be emphasised that Ni/PANI-AC owns the reduction peak with highest intensity at low temperature, indicating the higher amount of small $\mathrm{Ni}$ particles for Ni/PANI-AC. The main peak observed in the TPR profiles $\left(350-450{ }^{\circ} \mathrm{C}\right)$ can be attributed to the reduction of medium-sized Ni particles. Notably, the addition of $\mathrm{N}$ in the $\mathrm{C}$ structure lowers the reduction temperature of $\mathrm{NiO}$ species, as shown by the main peak shifted to a low temperature range. We can then infer a promotional effect of $\mathrm{N}$ on the redox properties of the catalysts being the $\mathrm{N}$-doped materials easier to reduce than that on non-doped carbon materials, in fair agreement with previous studies [28]. The enhanced reducibility of $\mathrm{Ni} / \mathrm{NC}$ could be attributed to the electronic interactions aroused by doping electron-rich nitrogen, resulting in better dispersion of Ni particles on the surface of carbon material.

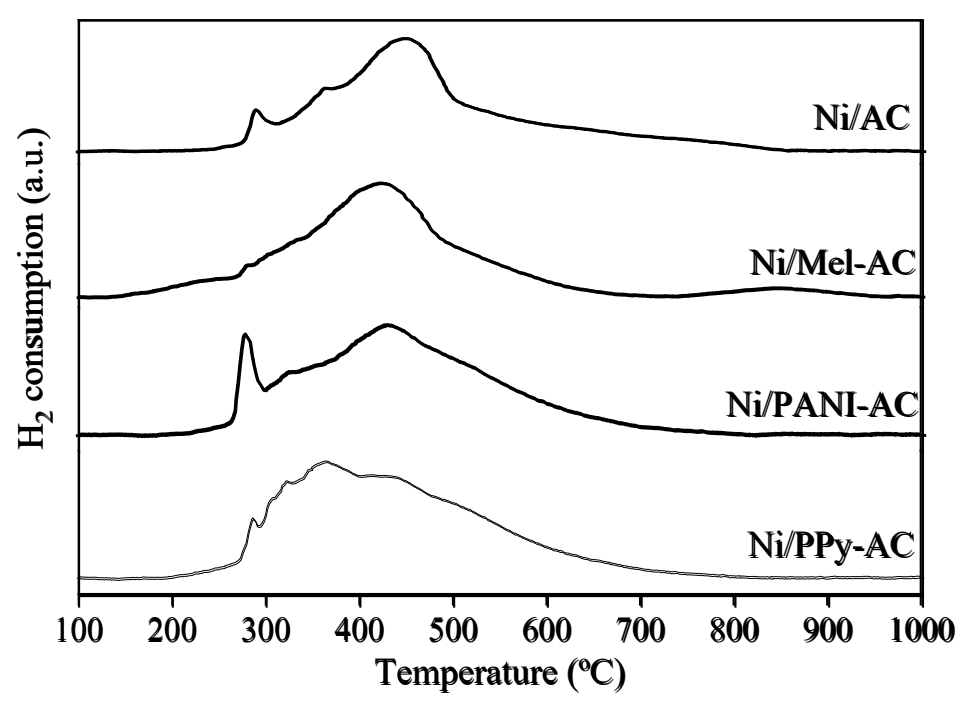

Figure $1 . \mathrm{H}_{2}$-TPR profile of the Ni-based catalysts

\section{Textural properties}

Table 1 summarised the textural features of the prepared materials including the surface area, pore volume and average pore diameter of calcined catalysts. The doping nitrogen procedure on the carbon structure noticeably decreased the specific surface area and pore volume of samples. Ni/Mel exhibited the highest surface area among N-doped samples, with a value of $551 \mathrm{~m}^{2} / \mathrm{g}$, followed by Ni/PANI-AC and Ni/PPy-AC $\left(441 \mathrm{~m}^{2} / \mathrm{g}\right.$ and $344 \mathrm{~m}^{2} / \mathrm{g}$, respectively). Results indicate that the mesopores of carbon support could be partially blocked by nitrogen-containing compounds during the nitrogen doping process. The difference in the loss of the textural parameters relates to the preparation routes of Ndoped carbon. The physical mixture route for the preparation of Mel-AC favours the doping of melamine on the outer surface of carbon, resulting in relatively low pore blocking effect. In contrast, polymerization process for the preparation of PPy-AC and PANI-AC takes place inside the pore, thus resulting in a more marked blocking effect.

Table 1 Textural properties of the studied catalysts

\begin{tabular}{llll}
\hline Catalyst & $\mathrm{S}_{\text {BET }}\left(\mathrm{m}^{2} / \mathrm{g}\right)$ & $\begin{array}{l}\text { Pore Volume }^{\mathrm{a}} \\
\left(\mathrm{cm}^{3} / \mathrm{g}\right)\end{array}$ & Pore size $^{\mathrm{b}}(\mathrm{nm})$ \\
\hline $\mathrm{Ni} / \mathrm{AC}$ & 1240 & 0.76 & 4.19 \\
$\mathrm{Ni} / \mathrm{Mel}-\mathrm{AC}$ & 551 & 0.36 & 4.07 \\
$\mathrm{Ni} /$ PPy-AC & 344 & 0.24 & 3.99
\end{tabular}




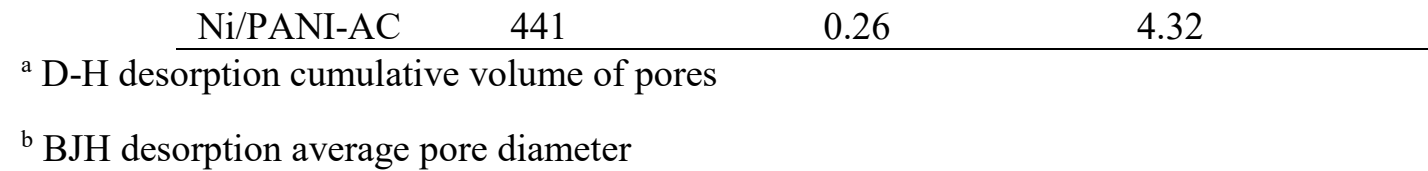

\section{XRD}

The XRD patterns of reduced Ni-based catalysts are depicted in Figure 2. The broad characteristic peak centred at around $24.5^{\circ}$ is associated to (002) plane reflection of carbon. The intensive diffraction peaks at around $44.5^{\circ}, 51.8^{\circ}$, and $76.4^{\circ}$ are attributed to the (111), (200) and (220) planes of the face-centeredcubic (fcc) structure of metallic Ni (JCPDS 87-0712) [29, 30]. The diffraction peaks at around $37.2^{\circ}$, $43.3^{\circ}$, and $62.9^{\circ}$ correspond to the (111), (200), and (220) planes, respectively, of NiO face-centeredcubic phase (JCPDS 04-0835) [30]. Slightly more notorious diffraction peaks of $\mathrm{NiO}$ can be observed for reduced $\mathrm{Ni} / \mathrm{AC}$, while $\mathrm{NiO}$ peaks are weak for reduced $\mathrm{Ni} / \mathrm{NC}$, especially for $\mathrm{Ni} / \mathrm{PPy}-\mathrm{AC}$ and $\mathrm{Ni} / \mathrm{PANI}-\mathrm{AC}$. This result indicated that doping nitrogen in carbon structure could enhance the reduction of $\mathrm{NiO}$ to metallic $\mathrm{Ni}$, which is consistence with the $\mathrm{H}_{2}-\mathrm{TPR}$ results. The promotion of $\mathrm{NiO}$ reduction is not obvious for $\mathrm{Ni} / \mathrm{Mel}-\mathrm{AC}$ sample since a clear $\mathrm{NiO} \mathrm{X}$-ray reflection peak can be found the diffraction pattern. Interestingly, sharper $\mathrm{Ni}^{0}$ peaks are observed in the XRD of $\mathrm{Ni} / \mathrm{PPy}-\mathrm{AC}$ compared to that of Ni/PANI-AC, indicating smaller particle size and greater dispersion of the $\mathrm{Ni}^{0}$ cluster within the Ni/PANI-AC catalyst.

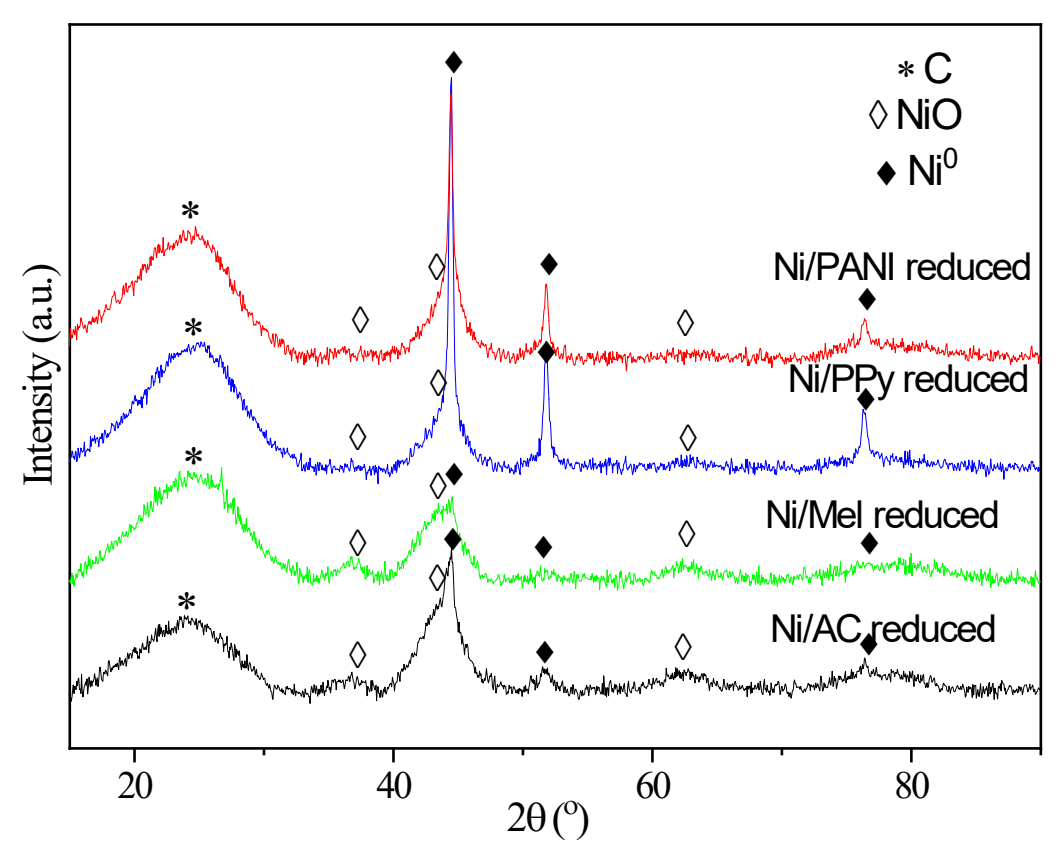

Figure 2. XRD patterns of reduced Ni-based catalysts

\section{XPS}

The surface chemistry of supports and Ni-based catalysts after reduction is examined by XPS analysis. XPS spectra of $\mathrm{N} 1 \mathrm{~s}$ and Ni $2 \mathrm{p}_{3 / 2}$ are presented in Figure 3, Figure 4 and Figure 5, respectively. The XPS spectra and relative atomic percentage of different types of $\mathrm{N}$ existing in the supports are presented in Figure S1. The binding energies of the main peaks and relative atomic percentage (at $\%$ ) of $\mathrm{N}$ for $\mathrm{Ni} / \mathrm{NC}$ catalysts are summarized in Table 2 . The XPS spectra of $\mathrm{N} \mathrm{1s} \mathrm{demonstrated} \mathrm{that} \mathrm{nitrogen} \mathrm{is}$ 
presented in different forms, including pyridinic (N6, centred at $398.2 \mathrm{eV})$, pyrrolic (N5, centred at $399.2 \mathrm{eV}$ ), quaternary (NQ, centred at $400.5 \mathrm{eV}$ ) and $\mathrm{N}$-oxides of pyridine nitrogen (NX, centred at $402.3 \mathrm{eV}$ ). The pyridinic-type nitrogen (N6) refers to the $\mathrm{N}$ contributing one p-electrons to the $\pi$-system. In contrast, pyrrolic-type nitrogen (N5) refers to the $\mathrm{N}$ with one more p-electrons to the $\pi$-system, which is composed of the contribution of pyridone, lactam and pyrrollic nitrogen groups. The quaternary-type nitrogen (NQ) is incorporated into the activated carbon structure and replaces a carbon atom, which normally includes protonated pyridine, or the namely "graphitic nitrogen". The oxidized nitrogen, pyridine oxide (NX) normally appears with the highest binding energy in the XPS spectra of N 1s [31, 32].

As shown in Figure 3, four types of $\mathrm{N}$ all exist for $\mathrm{NC}$ supports. Mel-AC owns the highest surface concentration of nitrogen (7.0 at.\%) comparing to PANI-AC (3.7 at.\%) and PPy-AC (3.0 at.\%). The difference in the surface concentration of nitrogen relates to preparation routes of NC supports. Physical mixture routes for Mel-AC favours the doping of $\mathrm{N}$ on the surface of support, resulting in higher surface concentration of nitrogen compared to supports prepared by polymerization process, including PANI$\mathrm{AC}$ and PPy-AC. N6 is dominated for Mel-AC while N5 and NQ are predominant ones for PANI-AC and PPy-AC (Figure 3). In terms of Ni/NC catalysts, four types of $\mathrm{N}$ are all observed for Ni/PPy-AC sample while part of type of nitrogen disappear for Ni/PANI-AC and Ni/Mel-AC (Figure 4). Specifically, N5 was not shown in Ni/PANI-AC. N5 and NX were not shown in Ni/Mel-AC (Figure 4). It is speculated that the disappeared N5 acts as coordinative sites for Ni ions, which means all of them were covered evidencing a close N-Ni interaction. NQ is predominant for all N-C supported catalysts. It can be observed that a higher surface concentration of nitrogen for $\mathrm{Ni} / \mathrm{Mel}-\mathrm{AC}$ surface $(4.0 \mathrm{at} \%)$ exists compared to $\mathrm{Ni} / \mathrm{PANI}-\mathrm{AC}$ and $\mathrm{Ni} / \mathrm{PPy}-\mathrm{AC}$, with 2.2 at $\%$ and 3.3 at $\%$, respectively. It is interesting to find that higher degree for the losing of $\mathrm{N}$ occurred for Ni/PPy-AC catalyst after doping $\mathrm{Ni}$ on the support. N6 occupies a larger percentage for Ni/Mel-AC than Ni/PANI-AC and Ni/PPy-AC catalysts. It is reported that $\mathrm{N} 6$ sites could enhance both the coordination of metal ions and the anchoring of metal nanoparticles due to their electron-withdrawing capacity [33]. Indeed, Melke et. al found that the present of pyridinic-type nitrogen (N6) could result in smaller metal particle size while pyrrolictype nitrogen (N5) and graphic nitrogen (NQ) causes larger metal particle size [34].

Different nickel species exist on the surface of catalyst as shown in Ni $2 p_{3 / 2}$ spectra (Figure 3 ). The first band with low B.E at around 852-853 eV can be assigned to metallic nickel species. The following second and third peaks correspond to $\mathrm{Ni}^{2+}$ ions species as reported elsewhere [35, 36]. The binding energy of $\mathrm{Ni}^{0}$ slightly shift to a lower energy region for $\mathrm{Ni} / \mathrm{NC}$ compared to that of $\mathrm{Ni} / \mathrm{AC}$. Similar phenomenon can also be observed for Ni/NHPC (nitrogen-doped hierarchical porous carbon) [28]. Previous study reported that $\mathrm{Ni}$ atoms could bond to $\mathrm{N}$ atoms in the carbon skeleton [15]. The shift is probably due to $\mathrm{N}$ atoms and reflects a preferential electron donation to Ni nanoparticles. In comparison, the binding energy of $\mathrm{Ni}^{0}$ follow the order: $\mathrm{Ni} / \mathrm{PPy}<\mathrm{Ni} / \mathrm{PANI}<\mathrm{Ni} / \mathrm{Mel} \approx \mathrm{Ni} / \mathrm{AC}$. Also the $\mathrm{Ni} / \mathrm{C}$ ratio reported in Table 2 provides an idea of $\mathrm{Ni}$ dispersion of the samples' surface. Higher dispersion of $\mathrm{Ni}^{0}$ was achieved for Ni/PANI-AC (0.57) compared to that of Ni/Mel-AC (0.18) and Ni/PPy-AC (0.40). These results are indeed consistent with the TPR and XRD observations as high proportion of small $\mathrm{Ni}$ cluster with enhanced reducibility are present in the Ni/PANI-AC (Figure 1 and Figure 2).

In summary, $\mathrm{Ni} / \mathrm{PANI}-\mathrm{AC}$ is deemed as promising system since it owns more active sites $\left(\mathrm{Ni}^{0}\right)(\mathrm{XRD}$ and XPS) and highest proportion smaller Ni clusters (TPR) thus better dispersion of $\mathrm{Ni}$ is achieved on the support. Interestingly, $\mathrm{Ni} / \mathrm{Mel}-\mathrm{AC}$ owns the advantage of highest surface nitrogen content and concentration of N6 sites (XPS) and largest BET value while Ni/PPy presents strongest interaction among Ni-N-C (TPR and XPS). 


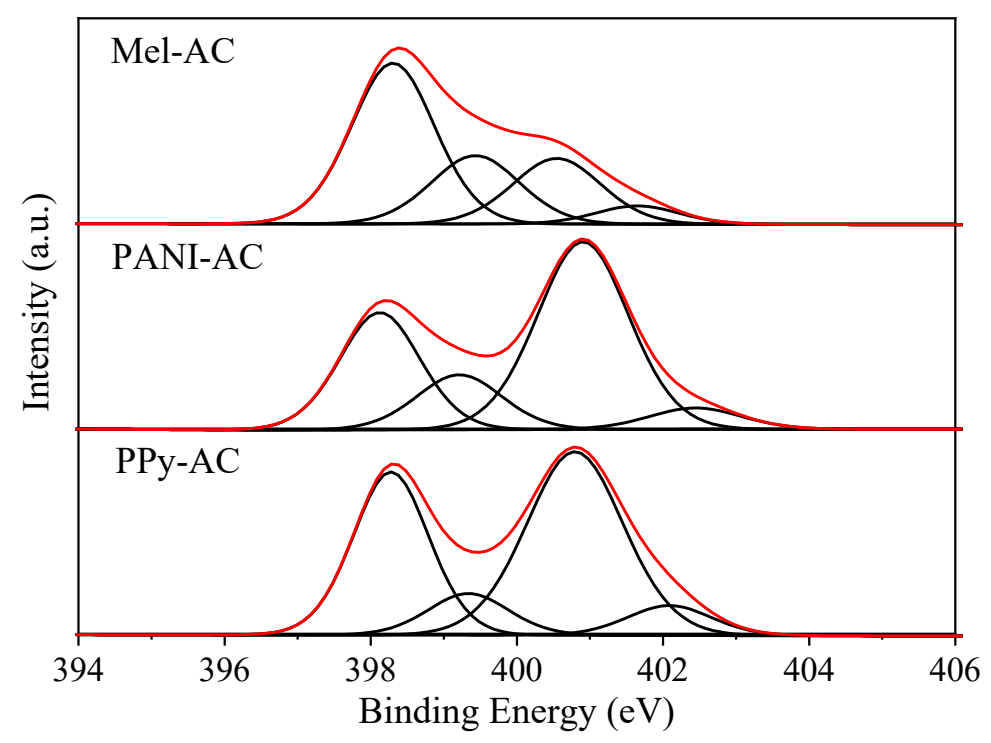

Figure 3 Core level XPS of N 1s region for nitrogen doped carbon supports after reduction treatment.

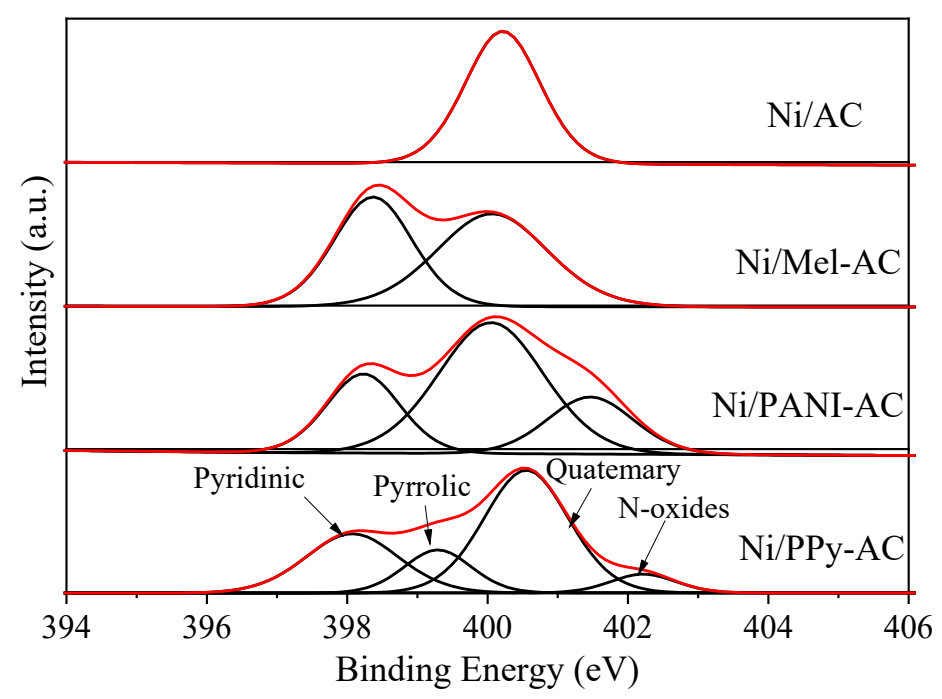

Figure 4. Core level XPS of N 1s region for Ni-based catalysts after reduction treatment. 


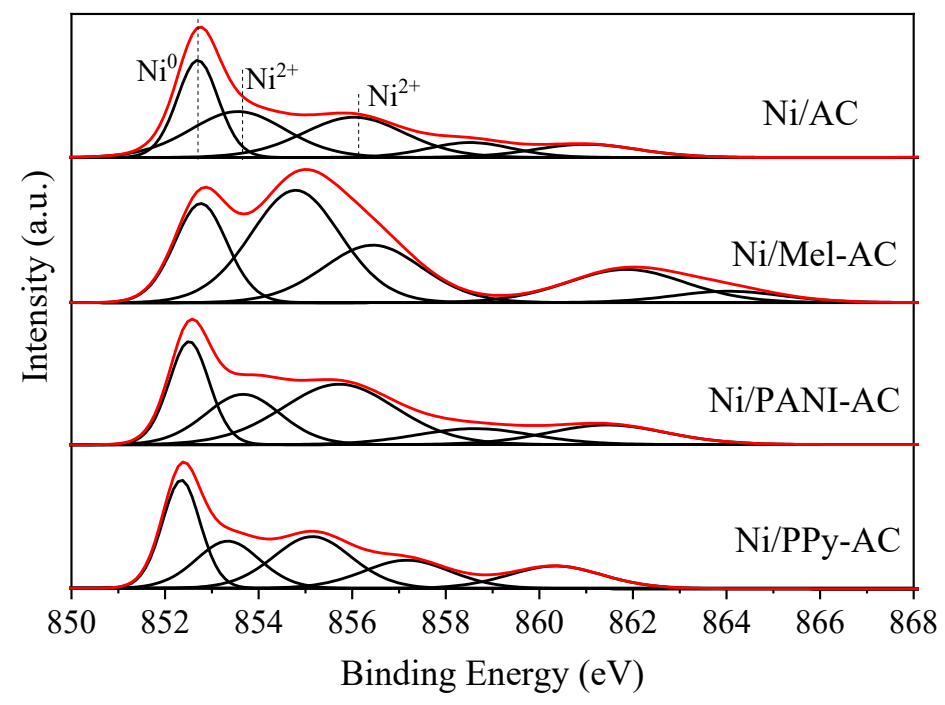

Figure 5. Core level XPS of Ni $2 \mathrm{p}_{3 / 2}$ spectra for Ni-based catalysts after reduction treatment

Table 2 Binding energies of and $\mathrm{Ni} 2 \mathrm{p}_{3 / 2}$ and $\mathrm{N}$ 1s levels of reduced catalysts and relative atomic percentage of different species

\begin{tabular}{|c|c|c|c|c|c|c|c|c|}
\hline \multirow{3}{*}{ Catalysts } & \multicolumn{3}{|c|}{ Ni $2 p_{3 / 2}$} & \multicolumn{5}{|c|}{$\mathrm{N} 1 \mathrm{~s}$} \\
\hline & $\mathrm{Ni}^{0}$ & $\mathrm{Ni}^{2+}$ & $\begin{array}{c}\mathrm{Ni}^{0} / \mathrm{C}^{*} \\
10^{2}\end{array}$ & $\mathrm{~N}$ & $\begin{array}{l}\text { Pyridinic N } \\
\text { (N6) }\end{array}$ & $\begin{array}{l}\text { Pyrrolic N } \\
\text { (N5) }\end{array}$ & $\begin{array}{l}\text { Quaternary } \\
\text { N (NQ) }\end{array}$ & $\begin{array}{l}\text { Pyridine } \\
\text { oxide N }\end{array}$ \\
\hline & $\begin{array}{l}\text { B.E. } \\
(\mathrm{eV})\end{array}$ & B.E. $(\mathrm{eV})$ & & at. $\%$ & B.E. $(\mathrm{eV})$ & B.E. $(\mathrm{eV})$ & B.E. $(\mathrm{eV})$ & B.E. $(\mathrm{eV})$ \\
\hline $\mathrm{Ni} / \mathrm{AC}$ & $\begin{array}{c}852.7 \\
(32.0 \%)\end{array}$ & $\begin{array}{c}853.6 \\
856.2 \\
(68.0 \%)\end{array}$ & 0.22 & & - & - & - & \\
\hline $\begin{array}{c}\text { Ni/Mel- } \\
\text { AC }\end{array}$ & $\begin{array}{c}852.8 \\
(25.4 \%)\end{array}$ & $\begin{array}{c}854.8 \\
856.4 \\
(74.6 \%)\end{array}$ & 0.18 & 4.02 & $\begin{array}{c}398.4 \\
(45.5 \%)\end{array}$ & - & $\begin{array}{c}400.1 \\
(54.5 \%)\end{array}$ & \\
\hline $\begin{array}{c}\text { Ni/PANI } \\
\text {-AC }\end{array}$ & $\begin{array}{c}852.5 \\
(28.0 \%)\end{array}$ & $\begin{array}{c}853.7 ; \\
855.8 \\
(72.0 \%)\end{array}$ & 0.57 & 2.22 & $\begin{array}{c}398.3 \\
(23.9 \%)\end{array}$ & - & $\begin{array}{c}400.1 \\
(56.3 \%)\end{array}$ & $\begin{array}{c}401.5 \\
(19.8 \%)\end{array}$ \\
\hline $\begin{array}{c}\text { Ni/PPy- } \\
\text { AC }\end{array}$ & $\begin{array}{c}852.4 \\
(36.2 \%)\end{array}$ & $\begin{array}{c}853.4 \\
855.2 \\
(63.8 \%)\end{array}$ & 0.40 & 3.27 & $\begin{array}{c}398.1 \\
(27.5 \%)\end{array}$ & $\begin{array}{c}399.3 \\
(14.4 \%)\end{array}$ & $\begin{array}{c}400.6 \\
(52.0 \%)\end{array}$ & $\begin{array}{c}402.2 \\
(6.1 \%)\end{array}$ \\
\hline
\end{tabular}

\section{Catalytic activity}

The catalytic activity of different Ni-based catalysts in guaiacol HDO process tested at $250{ }^{\circ} \mathrm{C}$ is shown in Figure 6. Remarkably, all catalysts with nitrogen doping in the carbon skeleton are more active than the undoped catalyst in terms of the guaiacol conversion. Specifically, the guaiacol conversion over the more active catalysts, Ni/PPy-AC and Ni/PANI-AC, increased by $4 \mathrm{~mol} \%$ and $8 \mathrm{~mol} \%$ respectively, compared to the results exhibited by the Ni/AC undoped catalyst. The addition of nitrogen provides Lewis basic sites which helps anchor and activate guaiacol. Besides, the nitrogen incorporation plays a vital role by inducing the formation of chemical bonding between the organic compound and the carbon material. The superior performance of Ni/PANI-AC can be attributed to its greater concentration of 
active sites which also benefit of larger dispersion of Ni particles as intended from the characterisation study

Three predominate monoaromatic compounds, including phenol, o-cresol and catechol is evident in the HDO process. Compounds with more complex structure, such as cyclopentane, 1,1,3-trimethyl; [1,1biphenyl]-4,4-diol, 3-3-dimethoxy-, were also observed as main products but not quantified. Catechol is the leading product among monoaromatic products for both catalytic and non-catalytic HDO process. It is typically produced through the demethylation (DME) of guaiacol along with the release of $\mathrm{CH}_{4}$. Unfortunately, the selectivity towards fully or almost fully deoxygenated products is modest and similar for all studied catalysts.

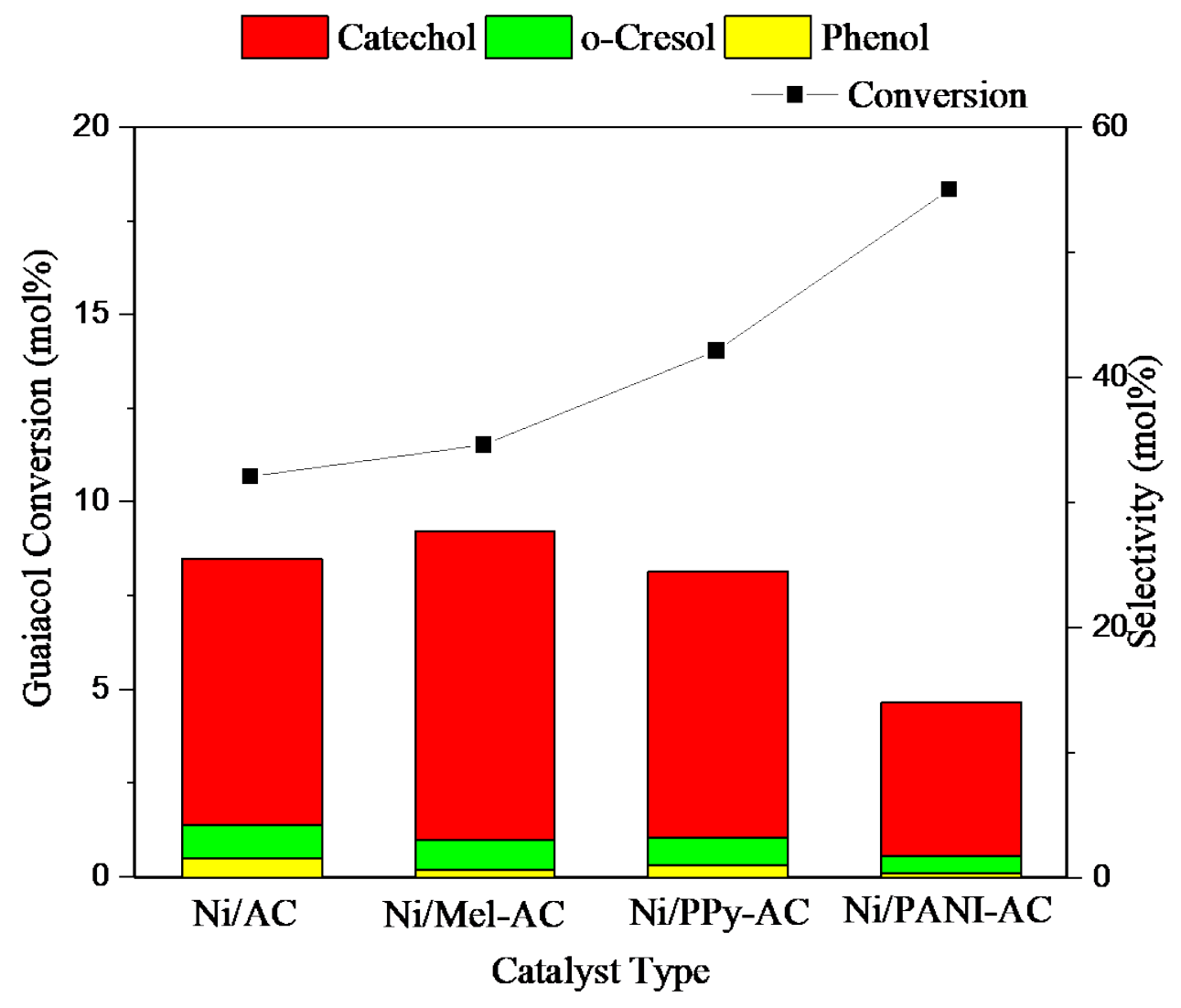

Figure 6. HDO of guaiacol over different Ni-based catalysts

Table 3 Catalytic hydrodeoxygenation of guaiacol over Ni-based catalysts

\begin{tabular}{|c|c|c|c|c|c|c|c|c|}
\hline $\begin{array}{l}\mathrm{N} \\
\mathrm{o}\end{array}$ & Catalyst & $\begin{array}{l}\text { Reacti } \\
\text { on } \\
\text { conditi } \\
\text { on } \\
\end{array}$ & $\begin{array}{l}\text { Hydrog } \\
\text { en } \\
\text { donor }\end{array}$ & $\begin{array}{c}\text { Conversi } \\
\text { on }\end{array}$ & Main products & $\begin{array}{l}\text { selectiv } \\
\text { ity }\end{array}$ & $\begin{array}{l}\text { React } \\
\text { or }\end{array}$ & Ref. \\
\hline 1 & $\begin{array}{c}15 \% \mathrm{Ni} / \mathrm{Al}_{2} \mathrm{O}_{3-} \\
\mathrm{SiO}_{2}\end{array}$ & $\begin{array}{l}\mathrm{T}=300 \\
{ }^{\circ} \mathrm{C} ; \\
\mathrm{P}=50 \\
\text { bar; } \\
\mathrm{t}=1 \mathrm{~h}\end{array}$ & $\mathrm{H}_{2}$ & $\approx 68 \%$ & $\begin{array}{c}\text { Methyl-guaiacol; } \\
\text { Phenol; } \\
\text { Cyclohexane; } \\
\text { Anisol; } \\
\text { Cresol; } \\
\text { benzene }\end{array}$ & $\begin{array}{l}\text { ₹25\%; } \\
\approx 14 \% ; \\
\approx 3 \% ; \\
\approx 2 \% \\
\approx 2 \% ;\end{array}$ & Batch & [37] \\
\hline
\end{tabular}




\begin{tabular}{|c|c|c|c|c|c|c|c|c|}
\hline & & & & & & $\approx 1 \%$ & & \\
\hline 2 & $\begin{array}{c}16.7 \% \mathrm{Ni} / \mathrm{TiO}_{2-}- \\
\mathrm{A}\end{array}$ & $\begin{array}{c}\mathrm{T}=300 \\
{ }^{\circ} \mathrm{C} ; \mathrm{P}=\mathrm{p} \\
\text { re } 40 \\
\text { bar } \\
\mathrm{T}=4 \mathrm{~h}\end{array}$ & $\mathrm{H}_{2}$ & $\approx 85 \%$ & $\begin{array}{l}\text { Phenol; } \\
\text { Cresol; }\end{array}$ & $\begin{array}{l}\approx 81 \% \\
\approx 15 \%\end{array}$ & Batch & [38] \\
\hline 3 & $\begin{array}{c}10 \% \mathrm{NiZr} / \mathrm{CMK} \\
-3\end{array}$ & $\begin{array}{l}\mathrm{T}=300 \\
{ }^{\circ} \mathrm{C} \\
\mathrm{P}=\text { pre } \\
50 \mathrm{bar} \\
\mathrm{T}=4 \mathrm{~h}\end{array}$ & $\mathrm{H}_{2}$ & $\approx 88 \%$ & $\begin{array}{l}\text { Cyclohexane; } \\
\text { Cyclohexanol; } \\
\text { methoxycyclohe } \\
\text { xanol }\end{array}$ & $\begin{array}{c}\approx 7.2 \% \\
\approx \\
35.5 \% \\
\approx \\
51.0 \%\end{array}$ & Batch & [39] \\
\hline 4 & $\begin{array}{c}\mathrm{Ni} / \mathrm{SiO} 2+\mathrm{H} \beta \\
\text { zeolite }\end{array}$ & $\begin{array}{c}\mathrm{T}=140 \\
\mathrm{oC} \\
\mathrm{P}=\text { pre } \\
30 \mathrm{bar} \\
\mathrm{T}=3 \mathrm{~h}\end{array}$ & $\mathrm{H}_{2}$ & $>99 \%$ & cyclohexane & $\begin{array}{l}\mathrm{Y} \approx \\
91.7 \%\end{array}$ & Batch & [40] \\
\hline 5 & $\begin{array}{c}15 \% \mathrm{Ni} 2 \% \mathrm{Mo} / \mathrm{C} \\
\mathrm{eO}_{2}-\mathrm{C}\end{array}$ & $\begin{array}{c}\mathrm{T}=250 \\
{ }^{\circ} \mathrm{C} \\
\mathrm{P}=50 \\
\text { bar } \\
\mathrm{t}=4 \mathrm{~h}\end{array}$ & $\mathrm{H}_{2} \mathrm{O}$ & $\approx 18 \%$ & $\begin{array}{l}\text { Phenol; } \\
\text { o-cresol; } \\
\text { Catechol }\end{array}$ & $\begin{array}{l}\approx 0.5 \% \\
\approx 1.5 \% \\
\approx 15.7 \%\end{array}$ & Batch & {$[26]$} \\
\hline 6 & $15 \% \mathrm{Ni} / \mathrm{AC}$ & $\begin{array}{c}\mathrm{T}=250 \\
{ }^{\circ} \mathrm{C} \\
\mathrm{P}=50 \\
\mathrm{bar} \\
\mathrm{t}=4 \mathrm{~h}\end{array}$ & $\mathrm{H}_{2} \mathrm{O}$ & $\approx 11 \%$ & $\begin{array}{l}\text { Phenol; } \\
\text { o-cresol; } \\
\text { Catechol }\end{array}$ & $\begin{array}{l}1.58 \% \\
2.70 \% \\
21.36 \%\end{array}$ & Batch & $\begin{array}{l}\text { Thi } \\
\text { s } \\
\text { stud } \\
\text { y }\end{array}$ \\
\hline 7 & $\begin{array}{c}15 \% \mathrm{Ni} / \mathrm{PANI}- \\
\mathrm{AC}\end{array}$ & $\begin{array}{c}\mathrm{T}=250 \\
{ }^{\circ} \mathrm{C} \\
\mathrm{P}=50 \\
\mathrm{bar} \\
\mathrm{t}=4 \mathrm{~h}\end{array}$ & $\mathrm{H}_{2} \mathrm{O}$ & $\approx 18 \%$ & $\begin{array}{l}\text { Phenol; } \\
\text { o-cresol; } \\
\text { Catechol }\end{array}$ & $\begin{array}{l}0.34 \% \\
1.39 \% \\
12.37 \%\end{array}$ & Batch & $\begin{array}{l}\text { Thi } \\
\text { s } \\
\text { stud } \\
\text { y }\end{array}$ \\
\hline
\end{tabular}

In order to stablish an accurate comparison with the current state of the art systems, Table 3 summarised some recent reported results of liquid-phase guaiacol HDO over Ni-based catalysts. Apparently, higher conversion of guaiacol and higher HDO degree was achieved in conventional $\mathrm{HDO}$ in which $\mathrm{H}_{2}$ is used as hydrogen source. The catalytic performance presented in this work and our previous study (ref. [26]) needs further improvement comparing with results of conventional HDO. However, we must emphasise that our HDO happens in $\mathrm{H}_{2}$-free reaction system, which is a very challenging an ambitus approach. Hence, although we achieve lower activity/selectivity results, our strategy deserves further consideration.

As a matter of fundamental understanding of the $\mathrm{H}_{2}$-free reaction and in order to rule out the possible contribution of hydrogen released from the functional groups of supports, a He-TPD analysis was conducted (Figure S2). It can be observed that $\mathrm{H}_{2}$ only be released from support at high temperature $\left(>400{ }^{\circ} \mathrm{C}\right.$ for Mel; $>800{ }^{\circ} \mathrm{C}$ for $\mathrm{AC}, \mathrm{PANI}-\mathrm{AC}$ and $\left.\mathrm{PPy}-\mathrm{AC}\right)$ which are certainly beyond the selected temperatures for our catalytic runs $\left(250^{\circ} \mathrm{C}\right)$. This is indeed an excellent indication that the support will not be the source of hydrogen for HDO at mild reaction condition and our approach relies on an autogenous source of hydrogen during the hydrothermal process. 


\section{Characterization of spent catalysts}

The XRD analysis of spent samples provides some information concerning the stability of catalysts, i.e. carbon decomposition and active phase changes can be identified. Figure 7 shows the XRD patterns of all spent samples. Generally, catalysts are likely to be oxidised by oxygen-containing intermediates under high temperature and pressure in a hydrothermal reaction media $\left(250{ }^{\circ} \mathrm{C}, 50 \mathrm{bar}\right)$. The typical diffraction peaks of metallic $\mathrm{Ni}$ at $2 \theta=44.5^{\circ}, 51.8^{\circ}$, and $76.4^{\circ}$ disappeared for $\mathrm{Ni} / \mathrm{AC}$ and $\mathrm{Ni} / \mathrm{Mel}$ spent catalysts. In contrast, they remain in $\mathrm{Ni} / \mathrm{PANI}$ and $\mathrm{Ni} / \mathrm{PPy}-\mathrm{AC}$ spent catalysts. These results agree well with the $\mathrm{XRD}$ of reduced catalysts since $\mathrm{Ni}^{0}$ is the main phase for $\mathrm{Ni} / \mathrm{PANI}-\mathrm{AC}$ and $\mathrm{Ni} / \mathrm{PPy}-\mathrm{AC}$. Besides, our observations pointed out that the addition of nitrogen in the carbon structure could stabilize metallic $\mathrm{Ni}$, especially for $\mathrm{Ni} / \mathrm{PANI}-\mathrm{AC}$ and $\mathrm{Ni} / \mathrm{PPy}-\mathrm{AC}$ catalysts. In other words, the electronic interaction $\mathrm{N}$ $\mathrm{Ni}$ prevents $\mathrm{Ni}$ oxidation resulting in a more robust catalysts for bio-compounds upgrading in hydrothermal conditions.

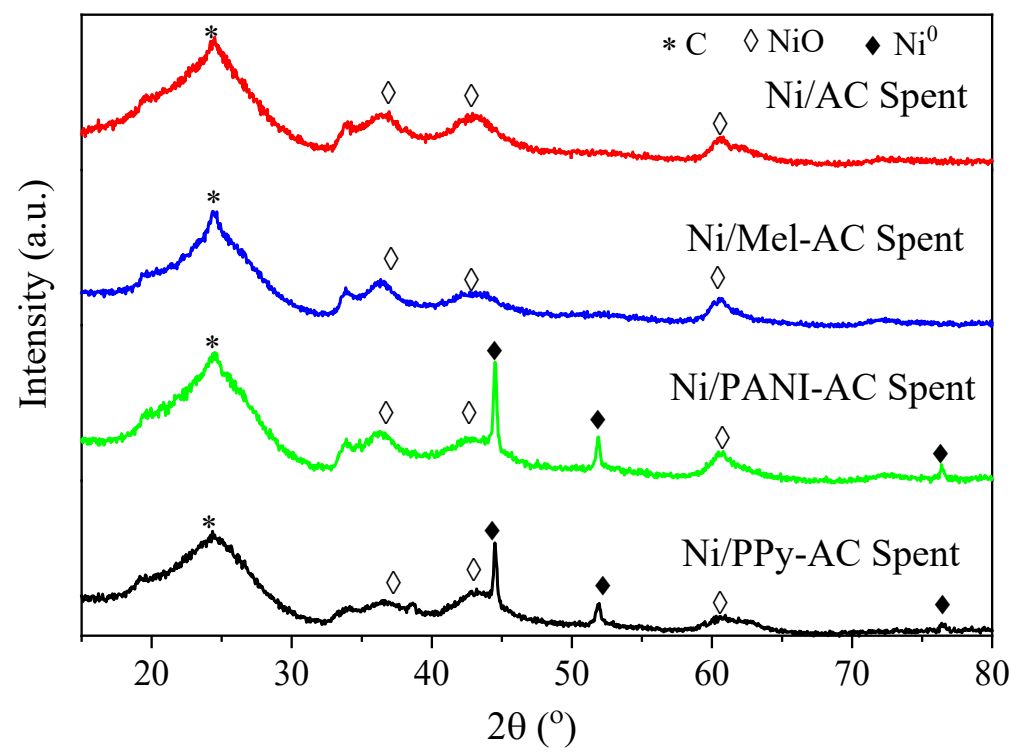

Figure 7. XRD of the Ni-based catalysts after the reaction

The XPS spectra of Ni 2 $p_{3 / 2}$ and N 1s were shown in Figure S3 and Figure S4 respectively. Peak related to metallic Ni disappeared, indicating that the metallic $\mathrm{Ni}$ on the surface of catalysts were all oxidised to $\mathrm{Ni}^{2+}$ during the HDO reaction (Figure S3). Hence, contrasting the XPS info with the XRD data it seems that we definitely have surface oxidation of $\mathrm{Ni}$ but still in the presence of $\mathrm{N}$ there is some remaining metallic Ni species in the bulk of the sample. As for the nitrogen evolution during the reaction, forms of nitrogen in NC supported catalyst significantly changed during HDO (Figure S4). It can be observed that $\mathrm{N} 5$ and $\mathrm{NX}$ no longer exist in Ni/PPy-AC after the HDO reaction. It is speculated that electronic transfer between $\mathrm{N}$ species and metal particles shifts the binding energy of $\mathrm{N} 5$ towards lower values, thus overlapping with the diffraction peak of N6. This would also explain the larger intensity of $\mathrm{N} 6$ for spent Ni/PPy-AC compared to reduced samples. It is also interesting to observe that new peak of NX were observed for spent $\mathrm{Ni} / \mathrm{Mel}$ evidencing further evolution of the $\mathrm{N}$ species during the reaction for this particular sample.

In order to visualize the structural and morphological changes of catalysts, TEM micrographs of fresh and spent catalysts were compared (Figure 8). Metal particles are well dispersed on carbon support being in principle the PANI sample the one with the greatest metallic dispersion in fair agreement with 
the XPS results. No metal sintering can be observed for both fresh and spent catalysts. This is in fact a plausible phenomenon since the HDO reaction happens in an aqueous media under relatively aggressive reaction conditions. In any case the absence of sintering is a highly commendable achievement which also validates the suitability of the developed catalysts for the H2-free HDO process in hydrothermal conditions.
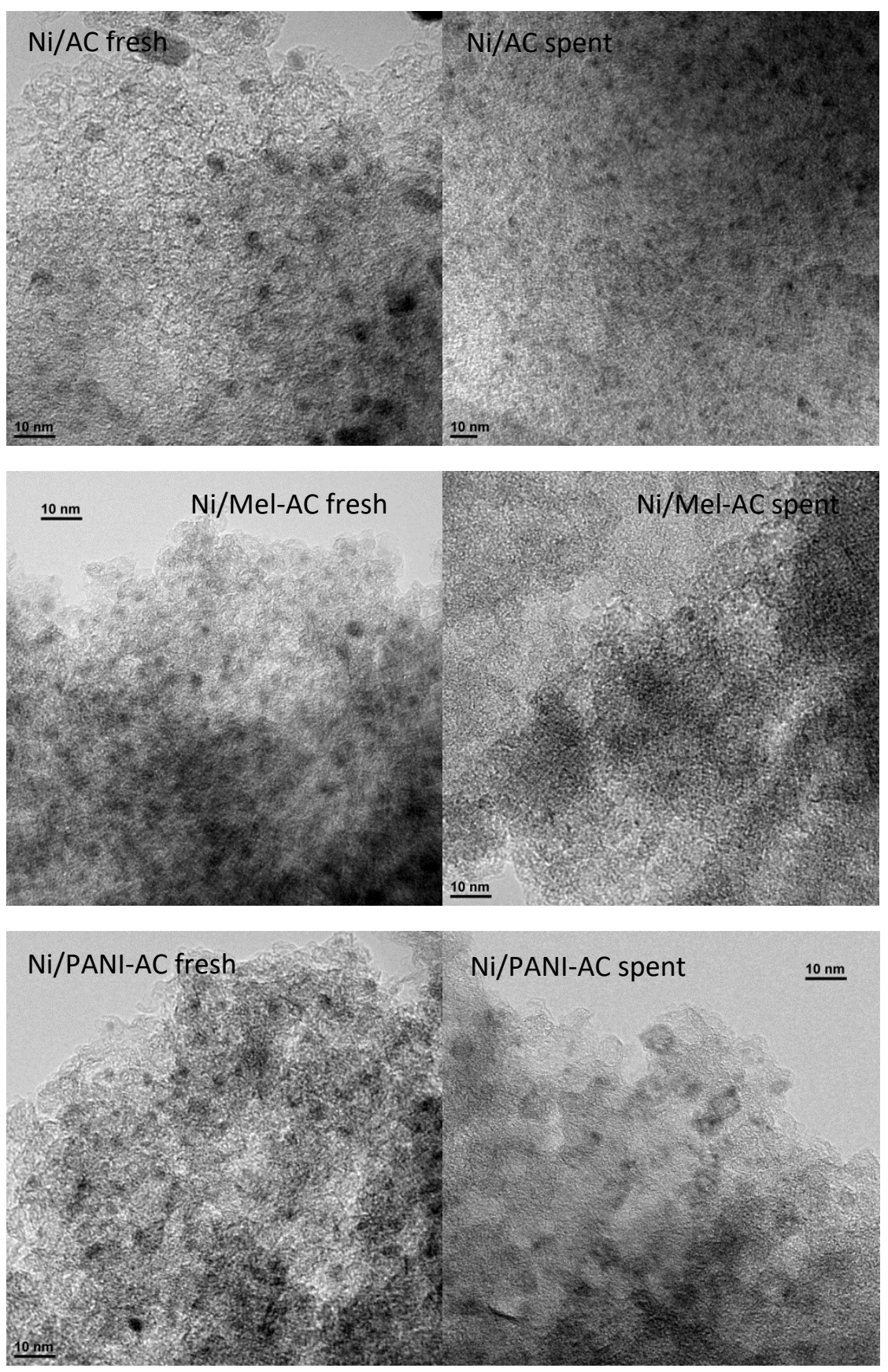


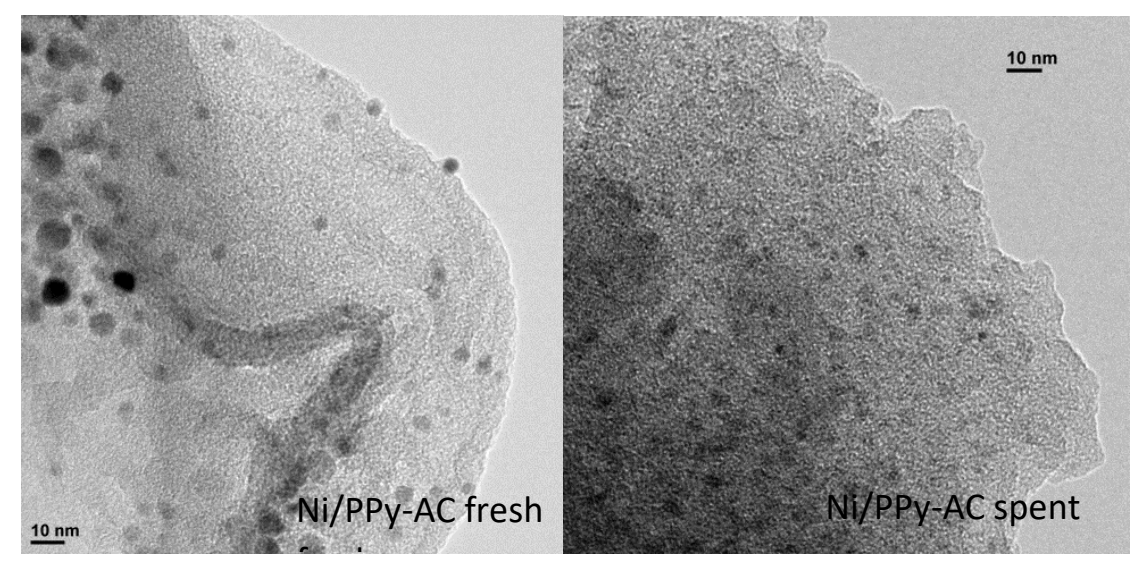

Figure 8 TEM images of reduced (fresh) and spent catalysts.

\section{Conclusions}

This work showcases a novel strategy for biomass valorisation via in-situ HDO process using economically appealing catalysts. Ni supported on N-doped carbon catalysts are proven to be effective model compounds HDO under hydrothermal conditions. When compared to the reference nitrogen-free sample the doped catalysts presented a better activity/selectivity balance indicating its superior catalytic behaviour. Such advantageous behaviour is ascribed to the electronic and acid-base properties modification arising from $\mathrm{N}$ introduction the carbon structure. Among the different sources of $\mathrm{N}$, $\mathrm{Ni} / \mathrm{PANI}-\mathrm{AC}$ is a more efficient than Ni/PPy-AC and Ni/Mel-AC. Indeed, the PANI system presented the highest concentration of metallic $\mathrm{Ni}$ atoms in the surface as well as the best dispersion and smaller $\mathrm{Ni}$ particles size among the studies series. Interestingly, surface area did not pose great effect on the catalytic activities. Presumably for real feedstocks (i.e. bigger molecules) the textural properties will play a more relevant role in the process. Importantly, no obvious metal sintering can be observed for spent samples, indicating some degree of robustness of catalysts under the studied conditions.

Despite the relatively modest performance results, this paper provides a new angle on bio-compounds conversion technologies. Certainly, the take home messages are: (i) we should pursue economically appealing routes for biomass conversion bypassing the need of external hydrogen supply (ii) $\mathrm{H}_{2}$-free HDO processes are achievable using water as reaction media (iii) advanced catalysts are needed to satisfy the conversion and selectivity requirements of a realistic application (iv) $\mathrm{Ni}$ dispersed on $\mathrm{N}$ doped carbons are promising candidates to be further explore in this challenging reaction.

\section{Reference}

[1] L. Hu, L. Lin, Z. Wu, S. Zhou, S. Liu, Recent advances in catalytic transformation of biomassderived 5-hydroxymethylfurfural into the innovative fuels and chemicals, Renewable Sustainable Energy Rev. 74 (2017) 230-257. https://doi.org/10.1016/j.rser.2017.02.042

[2] S. Proskurina, M. Junginger, J. Heinimö, B. Tekinel, E. Vakkilainen, Global biomass trade for energy - Part 2: Production and trade streams of wood pellets, liquid biofuels, charcoal, industrial roundwood and emerging energy biomass, Biofuels, Bioprod. Biorefin. 13 (2) (2019) 371-387. https://doi.org/10.1002/bbb.1858

[3] F. Mahfud, S. Bussemaker, B. Kooi, G. Ten Brink, H. Heeres, The application of water-soluble ruthenium catalysts for the hydrogenation of the dichloromethane soluble fraction of fast pyrolysis oil and related model compounds in a two phase aqueous-organic system, J. Mol. Catal. A: Chem. 277 (1-2) (2007) 127-136. https://doi.org/10.1016/j.molcata.2007.07.004

[4] X. Xu, Y. Li, Y. Gong, P. Zhang, H. Li, Y. Wang, Synthesis of palladium nanoparticles supported on mesoporous N-doped carbon and their catalytic ability for biofuel upgrade, J. Am. Chem. Soc. 134 (41) (2012) 16987-16990. https://doi.org/10.1021/ja308139s 
[5] W. Jin, J.L. Santos, L. Pastor-Perez, S. Gu, M.A. Centeno, T.R. Reina, Noble metal supported on activated carbon for "hydrogen free" HDO reactions: exploring economically advantageous routes for biomass valorisation, ChemCatChem, 11 (17) (2019) 4434-4441.

https://doi.org/10.1002/cctc.201900841

[6] S. Salakhum, K. Saenluang, C. Wattanakit, Stability of monometallic Pt and Ru supported on hierarchical HZSM-5 nanosheets for hydrodeoxygenation of lignin-derived compounds in the aqueous phase, Sustainable Energy Fuels, 4 (3) (2020) 1126-1134. DOI: 10.1039/C9SE00773C

[7] S. Jin, Z. Xiao, C. Li, X. Chen, L. Wang, J. Xing, W. Li, C. Liang, Catalytic hydrodeoxygenation of anisole as lignin model compound over supported nickel catalysts, Catal. Today, 234 (2014) 125 132. https://doi.org/10.1016/j.cattod.2014.02.014

[8] S. Mukundan, M. Konarova, L. Atanda, Q. Ma, J. Beltramini, Guaiacol hydrodeoxygenation reaction catalyzed by highly dispersed, single layered MoS2/C, Catal. Sci. Technol. 5 (9) (2015) 4422-4432. DOI: $10.1039 / \mathrm{C} 5$ CY00607D

[9] E. Haque, J.W. Jun, S.N. Talapaneni, A. Vinu, S.H. Jhung, Superior adsorption capacity of mesoporous carbon nitride with basic CN framework for phenol, J. Mater. Chem. 20 (2010) 1080110803. DOI: $10.1039 / \mathrm{C} 0 \mathrm{JM} 02974 \mathrm{~B}$

[10] T. Fu, M. Wang, W. Cai, Y. Cui, F. Gao, L. Peng, W. Chen, W. Ding, Acid-resistant catalysis without use of noble metals: carbon nitride with underlying nickel, ACS Catal. 4 (2014) 2536-2543. https://doi.org/10.1021/cs500523k

[11] Z. Wei, J. Wang, S. Mao, D. Su, H. Jin, Y. Wang, F. Xu, H. Li, Y. Wang, In situ-generated Co0$\mathrm{Co} 3 \mathrm{O} 4 / \mathrm{N}-$ doped carbon nanotubes hybrids as efficient and chemoselective catalysts for hydrogenation of nitroarenes, ACS Catal. 5 (2015) 4783-4789.

https://doi.org/10.1021/acscatal.5b00737

[12] R. Nie, M. Miao, W. Du, J. Shi, Y. Liu, Z. Hou, Selective hydrogenation of CC bond over Ndoped reduced graphene oxides supported Pd catalyst, Appl. Catal., B 180 (2016) 607-613. https://doi.org/10.1016/j.apcatb.2015.07.015

[13] G.H. Wang, Z. Cao, D. Gu, N. Pfänder, A.C. Swertz, B. Spliethoff, H.J. Bongard, C. Weidenthaler, W. Schmidt, R. Rinaldi, Nitrogen-Doped Ordered Mesoporous Carbon Supported Bimetallic PtCo Nanoparticles for Upgrading of Biophenolics, Angew. Chem., Int. Ed. 55 (2016) 8850-8855. https://doi.org/10.1002/anie.201511558

[14] R. Nie, X. Peng, H. Zhang, X. Yu, X. Lu, D. Zhou, Q. Xia, Transfer hydrogenation of bio-fuel with formic acid over biomass-derived N-doped carbon supported acid-resistant Pd catalyst, Catal.

Sci. Technol. 7 (2017) 627-634. DOI: 10.1039/C6CY02461K

[15] R. Nie, H. Yang, H. Zhang, X. Yu, X. Lu, D. Zhou, Q. Xia, Mild-temperature

hydrodeoxygenation of vanillin over porous nitrogen-doped carbon black supported nickel nanoparticles, Green Chem. 19 (2017) 3126-3134. DOI: 10.1039/C7GC00531H

[16] A. Zhao, J. Masa, M. Muhler, W. Schuhmann, W. Xia, N-doped carbon synthesized from Ncontaining polymers as metal-free catalysts for the oxygen reduction under alkaline conditions, Electrochim. Acta, 98 (30) (2013) 139-145. https://doi.org/10.1016/j.electacta.2013.03.043

[17] L. Jiang, L. Gao, Modified carbon nanotubes: an effective way to selective attachment of gold nanoparticles, Carbon, 41 (2003) 2923-2929. https://doi.org/10.1016/S0008-6223(03)00339-7

[18] X. Li, Z.-Y. Sui, Y.-N. Sun, P.-W. Xiao, X.-Y. Wang, B.-H. Han, Polyaniline-derived hierarchically porous nitrogen-doped carbons as gas adsorbents for carbon dioxide uptake,

Microporous Mesoporous Mater. 257 (2018) 85-91. https://doi.org/10.1016/j.micromeso.2017.08.027

[19] M.K. Rybarczyk, M. Lieder, M. Jablonska, N-doped mesoporous carbon nanosheets obtained by pyrolysis of a chitosan-melamine mixture for the oxygen reduction reaction in alkaline media, RSC

Adv. 5 (2015) 44969-44977. DOI: 10.1039/C5RA05725F

[20] W. Jin, L. Pastor-Perez, D. Shen, A. Sepulveda-Escribano, S. Gu, T.R. Reina, Catalytic upgrading of biomass model compounds: Novel approaches and lessons learnt from traditional hydrodeoxygenation-a review, ChemCatChem, 11 (3)(2019) 924-960.

https://doi.org/10.1002/cctc.201801722

[21] W. Jin, L. Pastor-Pérez, J. Yu, J. Odriozola, S. Gu, T. Reina, Cost-effective routes for Catalytic Biomass Upgrading, Current Opinion in Green and Sustainable Chemistry, 23 (2020) 1-9.

https://doi.org/10.1016/j.cogsc.2019.12.008 
[22] A.A. Dwiatmoko, L. Zhou, I. Kim, J.-W. Choi, D.J. Suh, J.-M. Ha, Hydrodeoxygenation of lignin-derived monomers and lignocellulose pyrolysis oil on the carbon-supported Ru catalysts, Catal. Today, 265 (2016) 192-198. https://doi.org/10.1016/j.cattod.2015.08.027

[23] H. Ohta, B. Feng, H. Kobayashi, K. Hara, A. Fukuoka, Selective hydrodeoxygenation of ligninrelated 4-propylphenol into n-propylbenzene in water by Pt-Re/ZrO2 catalysts, Catal. Today, 234 (2014) 139-144. https://doi.org/10.1016/j.cattod.2014.01.022

[24] B. Feng, H. Kobayashi, H. Ohta, A. Fukuoka, Aqueous-phase hydrodeoxygenation of 4propylphenol as a lignin model to n-propylbenzene over Re-Ni/ZrO2 catalysts, J. Mol. Catal. A: Chem. 388 (2014) 41-46. https://doi.org/10.1016/j.molcata.2013.09.025

[25] S. Cheng, L. Wei, M.R. Alsowij, F. Corbin, J. Julson, E. Boakye, D. Raynie, In situ hydrodeoxygenation upgrading of pine sawdust bio-oil to hydrocarbon biofuel using $\mathrm{Pd} / \mathrm{C}$ catalyst, $\mathrm{J}$. Energy Inst. 91 (2) (2018) 163-171. https://doi.org/10.1016/j.joei.2017.01.004

[26] W. Jin, L. Pastor-Pérez, J.J. Villora-Picó, A. Sepúlveda-Escribano, S. Gu, T.R. Reina, Investigating New Routes for Biomass Upgrading:"H2-Free" Hydrodeoxygenation Using Ni-Based Catalysts, ACS Sustainable Chem. Eng. 7 (19) (2019) 16041-16049.

https://doi.org/10.1021/acssuschemeng.9b02712

[27] R. Olcese, M. Bettahar, D. Petitjean, B. Malaman, F. Giovanella, A. Dufour, Gas-phase hydrodeoxygenation of guaiacol over Fe/SiO2 catalyst, Appl. Catal., B 115 (2012) 63-73. https://doi.org/10.1016/j.apcatb.2011.12.005

[28] M. Li, J. Deng, Y. Lan, Y. Wang, Efficient Catalytic Hydrodeoxygenation of Aromatic Carbonyls over a Nitrogen-Doped Hierarchical Porous Carbon Supported Nickel Catalyst, ChemistrySelect, 2 (2017) 8486-8492. https://doi.org/10.1002/slct.201701950

[29] L. García-Cerda, K. Bernal-Ramos, S.M. Montemayor, M. Quevedo-López, R. BetancourtGalindo, D. Bueno-Báques, Preparation of hep and fcc Ni and Ni/NiO nanoparticles using a citric acid assisted pechini-type method, J. Nanomater. 2011 (2011). https://doi.org/10.1155/2011/162495

[30] X. Kong, Y. Zhu, H. Zheng, X. Li, Y. Zhu, Y.-W. Li, Ni nanoparticles inlaid nickel phyllosilicate as a metal-acid bifunctional catalyst for low-temperature hydrogenolysis reactions, ACS Catal. 5 (10) (2015) 5914-5920. https://doi.org/10.1021/acscatal.5b01080

[31] B.J. Matsoso, K. Ranganathan, B.K. Mutuma, T. Lerotholi, G. Jones, N.J. Coville, Timedependent evolution of the nitrogen configurations in N-doped graphene films, RSC adv. 6 (2016) 106914-106920. DOI: 10.1039/C6RA24094A

[32] R. Arrigo, M. Hävecker, R. Schlögl, D.S. Su, Dynamic surface rearrangement and thermal stability of nitrogen functional groups on carbon nanotubes, Chemical Communications, (2008) 48914893.

[33] X. Ning, H. Yu, F. Peng, H. Wang, Pt nanoparticles interacting with graphitic nitrogen of Ndoped carbon nanotubes: effect of electronic properties on activity for aerobic oxidation of glycerol and electro-oxidation of CO, J. catal. 325 (2015) 136-144. https://doi.org/10.1016/j.jcat.2015.02.010 [34] J. Melke, B. Peter, A. Habereder, J. Ziegler, C. Fasel, A. Nefedov, H. Sezen, C. Wöll, H. Ehrenberg, C. Roth, Metal-support interactions of platinum nanoparticles decorated N-doped carbon nanofibers for the oxygen reduction reaction, ACS Appl. Mater. Interfaces, 8 (1) (2016) 82-90. https://doi.org/10.1021/acsami.5b06225

[35] T. Zeng, H. Zhang, Z. He, J. Chen, S. Song, Mussel-inspired approach to constructing robust cobalt-embedded $\mathrm{N}$-doped carbon nanosheet toward enhanced sulphate radical-based oxidation, Sci. rep. 6 (2016) 33348. https://doi.org/10.1038/srep33348

[36] I. Czekaj, F. Loviat, F. Raimondi, J. Wambach, S. Biollaz, A. Wokaun, Characterization of surface processes at the Ni-based catalyst during the methanation of biomass-derived synthesis gas: X-ray photoelectron spectroscopy (XPS), Appl. Catal., A 329 (2007) 68-78.

https://doi.org/10.1016/j.apcata.2007.06.027

[37] F. Broglia, L. Rimoldi, D. Meroni, S. De Vecchi, M. Morbidelli, S. Ardizzone, Guaiacol hydrodeoxygenation as a model for lignin upgrading. Role of the support surface features on Ni-based alumina-silica catalysts, Fuel, 243 (1) (2019) 501-508. https://doi.org/10.1016/j.fuel.2019.01.157 [38] X. Zhang, P. Yan, B. Zhao, K. Liu, M.C. Kung, H.H. Kung, S. Chen, Z.C. Zhang, Selective hydrodeoxygenation of guaiacol to phenolics by Ni/anatase $\mathrm{TiO} 2$ catalyst formed by cross-surface migration of Ni and TiO2, ACS Catal. 9 (2019) 3551-3563. https://doi.org/10.1021/acscatal.9b00400 
[39] M. Lopez, R. Palacio, S. Royer, A.-S. Mamede, J.J. Fernandez, Mesostructured CMK-3 carbon supported $\mathrm{Ni}-\mathrm{ZrO} 2$ as catalysts for the hydrodeoxygenation of guaiacol, Microporous Mesoporous Mater. 292 (15) (2020) 109694. https://doi.org/10.1016/j.micromeso.2019.109694

[40] X. Wang, S. Zhu, S. Wang, Y. He, Y. Liu, J. Wang, W. Fan, Y. Lv, Low temperature hydrodeoxygenation of guaiacol into cyclohexane over $\mathrm{Ni} / \mathrm{SiO} 2$ catalyst combined with $\mathrm{H} \beta$ zeolite, RSC adv. 9 (2019) 3868-3876. DOI: 10.1039/C8RA09972C 